\title{
Ultrasonographic examination of the spinal cord and collection of cerebrospinal fluid from the atlanto-occipital space in cattle
}

\author{
Braun, Ueli ; Attiger, Jeannette
}

\begin{abstract}
Ultrasonography is useful for the visualization of the spinal cord and associated structures and facilitates the safe collection of cerebrospinal fluid from the atlanto-occipital space in cattle. This technique is less stressful than the blind puncture technique because it does not require strong ventroflexion of the head. Furthermore, painful puncture of the spinal cord can largely be avoided when ultrasound guidance is used.
\end{abstract}

DOI: https://doi.org/10.1016/j.cvfa.2015.09.012

Posted at the Zurich Open Repository and Archive, University of Zurich

ZORA URL: https://doi.org/10.5167/uzh-125644

Journal Article

Accepted Version

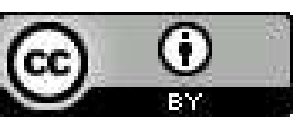

The following work is licensed under a Creative Commons: Attribution 4.0 International (CC BY 4.0) License.

Originally published at:

Braun, Ueli; Attiger, Jeannette (2016). Ultrasonographic examination of the spinal cord and collection of cerebrospinal fluid from the atlanto-occipital space in cattle. The Veterinary clinics of North America. Food animal practice, 32(1):109-118.

DOI: https://doi.org/10.1016/j.cvfa.2015.09.012 
1 Ultrasonographic examination of the spinal cord and collection of cerebrospinal fluid from the

2 atlanto-occipital space in cattle

3

4

5 Ueli Braun, Prof Dr med vet, Dr med vet h c, Dipl. ECBHM, Jeannette Attiger, Med Vet

6

7

8

9 Ueli Braun, Prof Dr Med Vet, Professor for Internal Medicine of Cattle, Department of Farm

10 Animals, University of Zurich, Winterthurerstrasse 260, CH-8057 Zurich, Switzerland

11 E-mail address: $\underline{\text { ubraun @ vetclinics.uzh.ch }}$

12 Telephone number: 0041-44-6358241

13 Fax number: 0041-44-6358904 


\section{Summary}

15 Ultrasonography is useful for the visualization of the spinal cord and associated structures and

16 facilitates the safe collection of cerebrospinal fluid from the atlanto-occipital space in cattle.

17 This technique is less stressful than the blind puncture technique because it does not require

18 strong ventroflexion of the head. Furthermore, painful puncture of the spinal cord can largely

19 be avoided when ultrasound guidance is used. Ultrasonographic examination of the spinal

20 cord between the 5th and 6th lumbar vertebrae or from the lumbosacral foramen is feasible in

21 calves and has been used to diagnose diplomyelia.

22

23 KEYWORDS

24 - Cattle $\cdot$ Ultrasonography $\cdot$ Spinal cord $\cdot$ Atlanto-occipital space $・$ Cerebrospinal fluid 


\section{Introduction}

The examination of cerebrospinal fluid (CSF) plays a major role in the diagnosis of central nervous system diseases in cattle. There are two sites from which CSF can be collected in cattle: the first is the atlanto-occipital (AO) space and the second is the lumbosacral foramen (LSF). ${ }^{1,2}$ The exact site of needle insertion at both locations is determined by skeletal landmarks but puncture is carried out blindly without visualization of the subarachnoid space. ${ }^{1-4}$ For collection from the AO space, the head is ventroflexed at a $90^{\circ}$ angle and the needle is inserted at the intersection between the dorsal midline and an imaginary line connecting the cranial edges of the wings of the atlas ${ }^{2,4}$ or slightly cranial to that intersection. ${ }^{1}$ A spinal needle is introduced into the subarachnoid space parallel to the longitudinal axis of the flexed head. ${ }^{1,4}$ The depth to which the needle is inserted is not exactly predictable, and the needle is advanced slowly and carefully and monitored for free flow of CSF by removing the stylet at regular intervals. ${ }^{2}$ Puncture of the spinal cord must be avoided because it can lead to nerve damage or even death of the patient. ${ }^{2,5}$ Strong ventroflexion of the head required for this technique often provokes avoidance movements in the animal and may impair respiration.

Furthermore, blind aspiration of CSF from the AO space frequently results in contamination of the sample with blood, ${ }^{6,7}$ which can impair the diagnosis. ${ }^{8-12}$ Finally, the spinal cord may be punctured during blind aspiration despite the precautions outlined above and results in pain evidenced by violent twitching. Based on experiences in the collection of CSF under ultrasonographic guidance in the horse, ${ }^{13-15}$ the spinal canal of cattle was examined ultrasonographically and the feasibility of ultrasound-guided collection of CSF investigated. ${ }^{16,17}$ Another study described the ultrasonographic findings of diplomyelia of the lumbar spine in a calf, ${ }^{18}$ and the ultrasonographic examination of the spinal cord in healthy calves was presented. ${ }^{19}$ The purpose of this article is to describe the ultrasonographic findings of the spinal cord and its surrounding structures and the ultrasound-guided collection of CSF from the AO space in cattle. 


\section{2 \\ Anatomy of the atlanto-occipital space}

The AO space is bordered by the occiput cranially and by the atlas caudally and is covered by the skin, the nuchal ligament, various muscles, and the AO membrane. ${ }^{2,20}$ Ventral to this membrane is the cranial-most section of the vertebral canal, which contains the spinal cord surrounded by three meninges. The outermost meninx is the dura mater, which is separated from the vertebral periosteum by the epidural space. ${ }^{21}$ The middle meninx is the dura arachnoidea, which is enveloped by the dura mater and consists of three layers. The outermost layer is made up of fibrocytes and collagen fibers and is separated from the dura mater by a so-called neurothelium. Avascular bundles of collagen fibers covered by neurothelium, referred to as arachnoid trabeculae, connect the outer layer with the inner layer of the dura arachnoidea, which also consists of collagen fibers and fibrocytes. ${ }^{21,22}$ These trabeculae are in the middle layer and form a spider web-like network surrounded by CSF. The middle layer of the dura arachnoidea is referred to as the subarachnoid space ${ }^{22}$ and contains the arteries that supply the central nervous system. ${ }^{21}$ The innermost layer of the dura arachnoidea follows the superficial surface of the brain and spinal cord, whereas the outermost layer, together with the dura mater, forms a straight sac, which envelops the spinal cord. The innermost meninx, the pia mater, adheres to the surface of the brain and spinal cord and closely follows their contours. Cerebrospinal fluid-filled spaces referred to as subarachnoid cisternae are formed in the regions where the dura arachnoidea and pia mater separate over depressions in the brain or spinal cord. The cerebellomedullary cistern, also called the cisterna magna, is formed between the caudal aspect of the cerebellum and the medulla oblongata and in most domestic animals is of clinical importance for the collection of CSF from the AO space. ${ }^{21,22}$ However, in cattle, the cerebellomedullary cistern cannot be accessed because of the caudal elongation of the occipital bone, and therefore the caudal extension of the cistern is punctured for collection of 
CSF. ${ }^{23}$ The pia mater consists of loose connective tissue including blood vessels and nerves. It is tightly associated with the surface of the brain and spinal cord and is adjacent to the superficial glial cells of the central nervous system. The pia mater forms two narrow fibrous strips on either side of the spinal cord, called denticulate ligaments, with extensions that attach to the dura mater and provide stability to the spinal cord within the dural sac. ${ }^{21,22}$

The spinal cord is a cylindrical structure characterized by a dorsal median sulcus, two dorso-lateral sulci and a deep ventral median fissure. The dorsal afferent nerve roots enter the spinal cord at the dorso-lateral sulci, and the efferent nerve roots exit the spinal cord ventrolaterally on both sides. The dorsal and ventral nerve roots unite in the subarachnoid space to form the spinal nerves, which exit the spinal canal through the intervertebral foramina. In the center of the spinal cord is the central canal, which is continuous with the ventricular system of the brain. ${ }^{22}$

\section{Ultrasonographic examination of the spinal cord from the AO space}

The ultrasonographic findings of the spinal cord and the collection of CSF under ultrasonographic guidance from the AO space in 73 cows immediately after euthanasia and in 14 live cattle of various age with central nervous disease were described. ${ }^{16,17}$

\section{Preparation of cattle for the ultrasonographic examination}

For ultrasonographic examination and collection of CSF, cattle are placed in lateral recumbency. Cows are sedated with 0.07 to $0.10 \mathrm{mg} / \mathrm{kg}$ xylazine intravenously, followed by $0.05 \mathrm{mg} / \mathrm{kg}$ xylazine intramuscularly depending on the level of sedation. The cow is then placed on a tilt table and all four legs and the head are secured with straps. A $15 \mathrm{~cm} \mathrm{x} 10 \mathrm{~cm}$ area over the AO space is clipped and cleaned with ethanol. The head is fixed to the table with a halter in mild ventroflexion (about $30^{\circ}$ ) to improve the ultrasonographic visibility of the 
101 spinal cord. Rarely, moderate ventroflexion of about $45^{\circ}$ is required for successful imaging of

102 the spinal cord and CSF collection but strong ventroflexion of $90^{\circ}$, which is needed for blind

103 CSF aspiration, is never required.

104

Technique of ultrasonographic examination

106 A 5.0- to 7.5-MHz linear or convex transducer is used and after the application of conductive

107 gel, the spinal cord and its surrounding structures are imaged in longitudinal and cross

108 section.

109

110

Ultrasonographic findings of the AO space

111 Ultrasonograms of the AO space show, from dorsal to ventral, the skin, the nuchal ligament,

112 various muscles including the rectus capitis minor und major muscles, the AO membrane, and

113 the vertebral canal, which is bordered by the hyperechoic dura mater. In longitudinal section,

114 the muscles appear as echoic structures with longitudinal striations, and the nuchal ligament is

115 hypoechoic. The spinal cord is seen as a hypoechoic band, some areas of which have a

116 heterogeneous internal structure (Fig. 1). It is surrounded dorsally (toward the skin) as well as

117 ventrally (away from the skin) by the subarachnoid space and is anechoic to hypoechoic and

118 sometimes has a heterogeneous internal structure. Blood vessels often seen dorsolateral and

119 adjacent to the dural sac can be interpreted as a venous sinus based on findings in the horse. ${ }^{13}$

120 In cross section, the spinal cord is circular and surrounded by the subarachnoid space (Fig. 2).

121 The hyperechoic denticulate ligaments are often seen on both sides of the spinal cord between

122 the pia mater and dura mater. The central canal is frequently seen as a hyperechoic spot in the

123 middle of the spinal cord. The pia mater appears as an echoic line adjacent to the spinal cord.

124 The dura mater and arachnoid membrane are also seen as a hyperechoic line but cannot be

125 differentiated. 
128 The ultrasonographically visible structures were measured to generate reference intervals for

129 the cows with central nervous system disorders. ${ }^{16,17}$ Optimal sagittal and transverse

130 ultrasonograms were frozen and various variables measured using the electronic cursors. The 131 measurements made in the longitudinal and transverse planes are very similar (Table 1). In

132 the longitudinal section, the distance between the skin and arachnoidea ranges from 30 to 52 $133 \mathrm{~mm}($ mean $\pm \mathrm{sd}=38.6 \pm 4 \mathrm{~mm})$ and the height of the subarachnoid spaces dorsal and ventral

134 to the spinal cord ranges from 5 to $12 \mathrm{~mm}(8.9 \pm 1.6 \mathrm{~mm})$ and from 4 to $11 \mathrm{~mm}$ (median $=8.4$

$135 \mathrm{~mm})$, respectively. The height of the spinal cord varies from 6 to $13 \mathrm{~mm}(9.9 \pm 1.2 \mathrm{~mm})$ and

136 the height of the entire dural sac from 20 to $34 \mathrm{~mm}(26.9 \pm 3 \mathrm{~mm})$. The spinal cord can be

137 seen in the sagittal plane over a distance of 19 to $72 \mathrm{~mm}(43.1 \pm 10.3 \mathrm{~mm})$.

139 Ultrasound-guided collection of CSF from the atlanto-occipital space

140 Preparation of cattle and CSF collection technique

141 After ultrasonography, the clipped area over the AO space is cleaned with iodine soap and

142 disinfected and the skin at the site of puncture is anesthetized using $5 \mathrm{ml}$ of $2 \%$ lidocaine. The

143 so-called freehand technique ${ }^{24}$ with a spinal needle $\left(0.90 \times 90 \mathrm{~mm}\right.$, Terumo ${ }^{\circledR}$ Spinal needle,

144 Terumo Medical Corporation, USA) is used to puncture the arachnoidea under

145 ultrasonographic guidance (Figs. 3, 4). Positioning the needle so that it is aligned perfectly

146 with the sagittal orientation of the sound waves can pose a problem initially, but this

147 technique becomes easier with practice and the accidental puncture of blood vessels can be

148 avoided. The needle is introduced in the median plane in a caudoventral direction. As

149 described for CSF collection in the horse, the angle between the needle and the dura mater is 150 critical. ${ }^{13,15}$ When the angle is too small, the needle does not perforate the dura mater but 
151 pushes it ventrally. This complication has occurred regardless of the angle of the needle and is

152 referred to as tenting in human medicine. ${ }^{25}$ The tenting phenomenon increases the risk of

153 accidental puncture of the spinal cord and must be avoided at all cost. After perforation of the

154 arachnoidea and observation of the tip of the needle in the subarachnoid space, the stylet is

155 removed and 3 to $5 \mathrm{ml}$ of CSF is aspirated using a syringe. If the attempt is unsuccessful, the

156 stylet is re-inserted and the needle withdrawn partly or completely and the puncture repeated

157 at a slightly different angle. A new needle is used after accidental puncture of a blood vessel

158 or aspiration of blood. When done correctly and without spinal cord puncture, this technique

159 does not elicit pain or avoidance behavior in cows.

160

161 Examination of the cerebrospinal fluid

162 Ultrasound-guided collection of CSF reduces the incidence of contamination of the CSF with

163 blood, which is common when the blind puncture technique is used. ${ }^{6,7}$ Therefore, most CSF

164 samples are clear and colorless but it must be remembered that blood contamination is not

165 always recognized macroscopically. ${ }^{7,9,10}$ In CSF samples collected under ultrasound guidance

166 at our clinic, the red blood cell count ranged from 0 to 820 erythrocytes/ $\mu 1 \mathrm{CSF}$ (median $=2.5$

167 erythrocytes/ $\mu$ l CSF) (Fig. 5). A minimum erythrocyte count of about 2,000 to 3,000 cells/ $\mu 1$

168 is required to render a CSF sample grossly discolored or turbid, ${ }^{8,9,26}$ which explains why

169 practically all of our samples appeared uncontaminated. It also means that CSF collected

170 using the described technique is well suited for diagnostic purposes in cattle with central

171 nervous system disease. It should also be noted that it is possible to collect a clean CSF

172 sample in a second attempt after a blood vessel has been punctured and hemorrhagic CSF

173 aspirated initially. This is a major advantage over the blind puncture technique, which usually

174 does not allow for the collection of a blood-free CSF sample at the same collection site once a

175 hemorrhagic sample or frank blood has been aspirated. 
177 Ultrasonographic examination of the spinal cord from the lumbosacral area in the calf

178 In calves, the spinal cord also can be examined ultrasonographically between the 5th and 6th

179 lumbar vertebrae or from the lumbosacral foramen ${ }^{18,19}$ but a detailed description of this

180 technique in adult cows was not available at the time of this writing. There are anecdotal

181 reports that lateral ultrasonograms of the spinal cord can be obtained at the lumbosacral

182 foramen in adult cows. A 7.5-MHz linear transducer is best suited for the examination in

183 calves. The calf is placed in lateral recumbency and positioned such that the lumbar vertebrae

184 are slightly arched dorsally. Similar to the technique described for the AO space, the spinal

185 cord and the surrounding structures are examined in the sagittal and transverse planes. The

186 ultrasonographic appearance of the spinal cord is analogous to that at the AO space except

187 that two spinal nerves are seen on transverse images. This technique allows for the diagnosis

188 of spinal cord malformations, for instance diplomyelia, which is duplication of the spinal cord

189 including the central canal. ${ }^{27}$

190

191 Conclusions

192 The spinal cord and its surrounding structures can readily be identified using ultrasonography.

193 Also, it is possible to collect cerebrospinal fluid without blood contamination. In addition,

194 ultrasound guidance eliminates the need for marked ventroflexion of the head, which in turn

195 minimizes defensive reactions that commonly occur when the blind technique is used.

196 Ultrasound-guided collection of CSF is convenient and safe and therefore the method of

197 choice for collection of CSF in cattle.

198

199 References 
1. Vandevelde M, Jaggy A, Lang J. Spezielle Untersuchungsmethoden. Untersuchung des Liquor cerebrospinalis (LCS); Entnahmetechnik. In: Vandevelde M, Jaggy A, Lang J, editors. Veterinärmedizinische Neurologie. Ein Leitfaden für Studium und Praxis. Berlin, Parey Buchverlag. 2001, pp. 63-9.

2. De Lahunta A, Glass E. Cerebrospinal fluid and hydrocephalus. In: De Lahunta A, Glass EN, editors. Veterinary Neuroanatomy and Clinical Neurology. St Louis, Saunders Elsevier. 2009, pp. 54-76.

3. Di Terlizzi R, Platt SR. The function, composition and analysis of cerebrospinal fluid in companion animals: Part II - Analysis. Vet J 2009; 180 (1): 15-32.

4. Kumar V, Kumar N. Diagnostic value of cerebrospinal fluid evaluation in veterinary practice: An overview. J Adv Vet Res 2012; 2 (3): 213-7.

5. Luján Feliu-Pascual A, Garosi L, Dennis R, Platt S. Iatrogenic brainstem injury during cerebellomedullary cistern puncture. Vet Radiol Ultrasound 2008; 49 (5): 467-71.

6. Averill DR. Examination of the cerebrospinal fluid. In: Kirk RW, editor. Current Veterinary Therapy: V. Small Animal Practice. Philadelphia, WB Saunders Company.

7. Kornhuber ME, Kornhuber J, Kornhuber AW, Hartmann GM. Positive correlation between contamination by blood and amino acid levels in cerebrospinal fluid of the rat. Neurosci Lett 1986; 69 (2): 212-5.

8. Ylitalo P, Heikkinen ER, Myllylä VV. Evaluation of sucessive collections of cisternal cerebrospinal fluid in rats, rabbits, and cats. Exp Neurol 1976; 50 (2): 330-6.

9. Miller MM, Sweeney CR, Russell GE, Sheetz RM, Morrow JK. Effects of blood contamination of cerebrospinal fluid on western blot analysis for detection of antibodies against Sarcocystis neurona and on albumin quotient and immunoglobulin G index in horses. J Am Vet Med Assoc 1999; 215 (1): 67-71. 
10. Sweeney CR, Russell GE. Differences in total protein concentration, nucleated cell count, and red blood cell count among sequential samples of cerebrospinal fluid from horses. J Am Vet Med Assoc 2000; 217 (1): 54-7.

11. Finno CJ, Packham AE, Wilson WD, Gardner IA, Conrad PA, Pusterla N. Effects of blood contamination of cerebrospinal fluid on results of indirect fluorescent antibody tests for detection of antibodies against Sarcocystis neurona and Neospora hughesi. J Vet Diagn Invest 2007; 19 (3): 286-9.

12. Doyle C, Solano-Gallego L. Cytologic interpretation of canine cerebrospinal fluid samples with low total nucleated cell concentration, with and without blood contamination. Vet Clin Pathol 2009; 38 (3): 392-6.

13. Audigié F, Tapprest J, Didierlaurent D, Denoix JM. Ultrasound-guided atlanto-occipital puncture for myelography in the horse. Vet Radiol Ultrasound 2004; 45 (4): 340-4.

14. Pease A, Behan A, Bohart G. Ultrasound-guided cervical centesis to obtain cerebrospinal fluid in the standing horse. Vet Radiol Ultrasound 2012; 53 (1): 92-5.

15. Depecker M, Bizon-Mercier C, Couroucé-Malblanc A. Ultrasound-guided atlantooccipital puncture for cerebrospinal-fluid analysis on the standing horse. Vet Rec 2014; 174 (2): 45.

16. Attiger J. Liquorentnahme aus dem Spatium atlanto-occipitale unter Ultraschallkontrolle beim Rind. 2014, Master-Thesis, University of Zurich.

17. Braun U, Attiger J, Brammertz C. Ultrasonographic examination of the spinal cord and collection of cerebrospinal fluid from the atlanto-occipital space in cattle. BMC Vet Res $2015 ; 11: 227$.

18. Testoni S, Franz S, Dalla Pria A, Cipone M, Gentile A. Sonographie zur Untersuchung des Wirbelkanals bei Kälbern mit neurologischen Symptomen. KTP 2014; 22: 125-130. 
19. Gentile A, Testoni S, Franz S, Dalla Pria A. Spinal cord: Ultrasonographic windows in calves. Proceedings XXVII World Buiatrics Congress, Lisbon, 2012, 154.

20. Popesko P. Rind, junge Färse. Medianschnitt durch den Kopf. In: Popesko P, editor. Atlas der topographischen Anatomie der Haustiere. Stuttgart, Enke Verlag. 2011, p 30.

21. Stoffel MH. Meningen. In: Stoffel MH, editor. Funktionelle Neuroanatomie für die Tiermedizin. Stuttgart: Enke Verlag. 2011, pp. 100-5.

22. König HE, Liebich HG, Červeny C. Nervensystem (Systema nervosum). In: König HE, Liebich HG, editors. Anatomie der Haussäugetiere: Lehrbuch und Farbatlas für Studium und Praxis. Stuttgart, Schattauer. 2005, pp. 485-556.

23. Berg R, Müller K. Hals und Brustwand. In: Budras KD, Buda S, editors. Atlas der Anatomie des Rindes. Supplement: Klinisch-funktionelle Anatomie. Hannover, Schlütersche Verlagsgesellschaft. 2007, pp. 14-5.

24. Tucker RL. Ultrasound-guided biopsy. In: Rantanen RW, McKinnon AO, editors. Equine Diagnostic Ultrasonography. Baltimore, Williams \& Wilkins. 1998, pp. 649-53.

25. Orrison WW, Eldevik OP, Sackett JF. Lateral C1-2 puncture for cervical myelography. Part III: Historical, anatomic, and technical considerations. Radiology 1983; 146 (2):

26. Patten BM. How much blood makes the cerebrospinal fluid bloody? J Am Med Assoc 1968; 206 (2): 378.

27. Testoni S, Grandis A, Diana A, Dalla Pria A, Cipone M, Bevilacqua D, Gentile A. Imaging diagnosis - ultrasonographic diagnosis of diplomyelia in a calf. Vet Radiol Ultrasound 2010; 51 (6): 667-9. 
271 Table 1

272 Ultrasonographic measurements of the vertebral canal at the atlanto-occipital space in 73

273 euthanized cattle (mm, mean \pm standard deviation, median, range) (reproduced from Braun et 274 al. ${ }^{17}$ )

\section{Section}

\begin{tabular}{|c|c|c|}
\hline Variable & Longitudinal & Transverse \\
\hline Distance between skin and arachnoidea & $\begin{array}{l}38.6 \pm 4 \\
(30-52) \\
\mathrm{n}=68\end{array}$ & $\begin{array}{l}39.5 \pm 4.2 \\
(32-52) \\
\mathrm{n}=73\end{array}$ \\
\hline $\begin{array}{l}\text { Depth of the subarachnoid space dorsal to the spinal } \\
\text { cord }\end{array}$ & $\begin{array}{l}8.9 \pm 1.6 \\
(5-12) \\
n=67\end{array}$ & $\begin{array}{l}9.2 \pm 1.6 \\
(6-13) \\
n=73\end{array}$ \\
\hline Diameter of spinal cord & $\begin{array}{l}9.9 \pm 1.2 \\
(6-13) \\
n=67\end{array}$ & $\begin{array}{l}10.1 \\
(8-15) \\
\mathrm{n}=72^{2}\end{array}$ \\
\hline $\begin{array}{l}\text { Depth of the subarachnoid space ventral to the spinal } \\
\text { cord }\end{array}$ & $\begin{array}{l}8.4 \\
(4-11) \\
\mathrm{n}=68\end{array}$ & $\begin{array}{l}8.8 \pm 1.8 \\
(5-14) \\
n=73\end{array}$ \\
\hline Diameter of entire dural sac & $\begin{array}{l}26.9 \pm 3 \\
(20-34) \\
\mathrm{n}=68\end{array}$ & $\begin{array}{l}28.2 \pm 3.5 \\
(21-40) \\
\mathrm{n}=73\end{array}$ \\
\hline Length of visible spinal cord & $\begin{array}{l}43.1 \pm 10.3 \\
(19-72) \\
n=67\end{array}$ & - \\
\hline
\end{tabular}




\section{Legend to Figures}

277 Fig. 1 Longitudinal ultrasonogram and schematic representation of the vertebral canal at the 278 level of the atlanto-occipital space obtained immediately after euthanasia in a 3.5-year-old 279 Swiss Braunvieh cow. Left is cranial and right is caudal. 1 Nuchal ligament, major and minor 280 rectus capitis muscles, 2 Atlanto-occipital membrane, 3 Subarachnoid space dorsal to the 281 spinal cord, 4 Spinal cord, 5 Central canal, 6 Subarachnoid space ventral to the spinal cord, A 282 Distance between skin and arachnoidea, B Depth of the subarachnoid space dorsal to the spinal cord, C Diameter of the spinal cord, D Depth of the subarachnoid space ventral to the 284 spinal cord.

Fig. 2 Transverse ultrasonogram and schematic representation of the vertebral canal at the level of the atlanto-occipital space obtained immediately after euthanasia in a 3.5-year-old Swiss Braunvieh cow. 1 Nuchal ligament, major and minor rectus capitis muscles, 2 Atlantooccipital membrane, 3 Subarachnoid space, 4 Spinal cord, 5 Denticulate ligaments, 6 Venous sinus within the epidural space, 7 Epidural space, A Distance between skin and arachnoidea,

291 B Depth of the subarachnoid space dorsal to the spinal cord, C Diameter of the spinal cord, D 292 Depth of the subarachnoid space ventral to the spinal cord.

Fig. 3. Collection of cerebrospinal fluid in a sedated cow in lateral recumbency. The head and legs are tied to the operating table. The fluid is collected from the atlanto-occipital space using a spinal needle and ultrasonographic guidance provided by a 5-MHz convex transducer.

Fig. 4. Schematic diagram of puncture of the subarachnoid space for collection of cerebrospinal fluid. The diagram is based on MRI images of the head of a 10-year-old Simmental cow. 1 Occiput, 2 Atlas, 3 Subarachnoid space, 4 Spinal cord. 
302 Fig. 5. Frequency distribution of different levels of blood contamination of cerebrospinal fluid 303 collected under ultrasound guidance in 73 cows. 